\title{
PENGELOLAAN DAN PENGENDALIAN AIR HUJAN DALAM PERUMAHAN SEBAGAI UPAYA KONSERVASI AIR TANAH
}

\section{MANAGEMENT AND CONTROL OF RAINWATER IN HOUSING FOR SOIL WATER CONSERVATION}

\author{
Daru Pratomo', Much. Suranto ${ }^{2}$ \\ 1,2 Jurusan Teknik Sipil-Fakultas Teknik-Universitas Widya Dharma Klaten \\ Jl. Ki Hajar Dewantoro Kec. Klaten Utara, Kabupaten Klaten, Jawa Tengah \\ Email: daru@unwidha.ac.id ${ }^{1}$; much.suranto@unwidha.ac.id ${ }^{2}$
}

\begin{abstract}
Overflow of rainwater causes flooding problems. Efforts to apply drainage techniques become an option in order to deal with global warming, namely the environmentally sound rainwater drainage system. This system according to [Sunjoto, 2007] consists of three groups, namely Rainwater Infiltration Well, Infiltration Trench and Recharge Yard and the latter is also called Taman Bertanggul (Sujono, 2005 ).The method used in this study using quantitative analysis methods. The sampling method is the purposive sampling method for the measurement of permeability which takes into account the sampling of land that has not been given pavement such as vacant land or yard while for measuring the depth of groundwater by measuring the depth of surface of existing well water and by exploring the infiltration well plan that will used in housing complexes.Based on the method calculation approach SNI 03-2453-2002 the need for infiltration wells to accommodate rainwater runoff due to the closure of open land by houses and carport as many as 20 units. Whereas as a substitute for land covered by paving blocks, 8 units were made. Dimensions of $1 \mathrm{~m}$ diameter infiltration well, $1.5 \mathrm{~m}$ depth for each infiltration well.
\end{abstract}

Keywords: Runoff; Absorption; Reservoir

\begin{abstract}
Abstrak
Limpahan air hujan yang tidak terkendali membuat masalah banjir. Usaha dalam menerapkan teknik drainase menjadi pilihan dalam rangka menghadapi global warming yaitu sistem drainase air hujan berwawasan lingkungan. Sistem ini menurut [Sunjoto, 2007] terdiri dari tiga kelompok yaitu Sumur Peresapan Air Hujan (Recharge Well), Parit Resapan Air Hujan (Recharge Trench) dan Taman Resapan Air (Recharge Yard) dan yang terakhir ini juga disebut Taman Bertanggul [Sujono, 2005].Metode yang digunakan dalam penelitian ini dengan menggunakan metode analisis kuantitatif. Pengambilan sampel dilakukan metode yaitu metode purposive sampling untuk pengukuran permeabilitas yang mempertimbangkan pengambilan sampel pada lahan yang belum diberi perkerasan seperti lahan kosong maupun pekarangan rumah sedangkan untuk pengukuran kedalaman muka air tanah dengan mengukur kedalaman permukaan air sumur eksisting dan dengan cara menggali rencana sumur resapan yang akan dipakai dalam komplek perumahan. Berdasarkan pendekatan perhitungan metode SNI 03-2453-2002 kebutuhan sumur resapan untuk menampung limpasan air hujan akibat dari tertutupnya lahan terbuka oleh rumah dan carport sebanyak 20 unit. Sedangkan sebagai pengganti lahan yang tertutup oleh paving block, dibuat 8 unit. Dengan dimensi sumur resapan diameter $1 \mathrm{~m}$, kedalaman 1,5 $\mathrm{m}$ atau 3 buah buis beton untuk setiap sumur resapan.
\end{abstract}

Kata kunci: limpasan permukaan; resapan air; tampungan air

\section{PENDAHULUAN}

Upaya memelihara keberadaan serta berkelanjutan keadaan, sifat, dan fungsi air tanah agar senantiasa tersedia dalam kuantitas dan kualitas yang memadai untuk memenuhi kebutuhan makhluk hidup, baik pada waktu sekarang maupun yang akan datang disebut konservasi air tanah. Pemakaian air tanah harus mempertimbangkan faktor kelestarian air tanah, yang meliputi faktor kualitas dan 
kuantitas air. Salah satu cara mempertahankan kuantitas air tanah adalah dengan menerapkan sumur resapan. Keuntungan yang dapat diperoleh dari pemanfaatan sumur resapan dapat menambah jumlah air tanah dan mengurangi jumlah limpasan. Limpahan air hujan yang begitu banyak dan tidak terkendali membuat masalah banjir. Air hujan yang berlebih apabila dikelola dengan baik dengan cara ditampung, diolah, dan dimanfaatkan kembali atau disimpan sebagai air cadangan sehingga ketika musim kemarau datang bisa dimanfaatkan sebagai sumber air bersih.

Air hujan masuk kedalam tanah secara alami terjadi pada daerah-daerah yang porous misalnya sawah, tanah lapangan, permukaan tanah yang terbuka, hutan, halaman rumah yang tidak tertutup dan lain-lain. Air hujan yang jatuh ke permukaan tanah pada awalnya akan membasahi tanah, bangunan, tumbuh-tumbuhan dan batuan. Ketika air hujan tersebut jatuh pada daerah yang berpori maka akan meresap kedalam tanah sebagai air infiltrasi, air tersebut semakin lama akan meresap lebih dalam lagi sampai memasuki daerah akuifer dan akirnya menjadi air tanah.Air tanah merupakan sumber air yang sangat penting bagi makhluk hidup. Air tanah tersebut tersimpan dalam lapisan yang disebut akuifer. Akuifer merupakan sumber air tanah yang sangat penting.

Dengan berubahnya fungsi lahan yang semula terbuka menjadi bangunan rumah dan sarana jalan sebagai akibatnya kemampuan lahan untuk meresapkan air hujan semakin berkurang yang dengan pasti akan menimbulkan peningkatan aliran permukaan atau surface runoff yang akibatnya menimbulkan berbagai genangan bahkan banjir di kala hujan terjadi. Air hujan yang dulu dengan mudah meresap kedalam tanah pada saat hujan saat ini sebagian lahan telah tertutup bangunan hingga terjadi limpasan permukaan (surface runoff) meningkat. Di sisi lain meningkatnya jumlah sarana prasarana ini telah menyebabkan berbagai dampak antara lain problema air tanah, problema polusi air dan problema banjir.

Proses pembangunan yang selalu terjadi dimanapun wilayah yang layak dihuni manusia senantiasa akan terjadi dan berkembang. Penelitian ini membatasi cakupan wilayah sempit di lokasi Klaster

\section{Perumahan Klaseman sebagai model} penelitian.

Fungsi lahan berubah yang semula terbuka menjadi bangunan rumah dan sarana jalan sebagai akibatnya kemampuan lahan untuk meresapkan air hujan semakin berkurang yang dengan pasti akan menimbulkan peningkatan aliran permukaan atau surface runoff yang akibatnya menimbulkan berbagai genangan bahkan banjir di kala hujan terjadi. Air hujan yang dulu dengan mudah meresap kedalam tanah pada saat hujan saat ini sebagian lahan telah tertutup bangunan hingga terjadi limpasan permukaan (surface runoff) meningkat. Di sisi lain menurut meningkatnya jumlah sarana prasarana ini telah menyebabkan berbagai dampak antara lain problema air tanah, problema polusi air dan problema banjir. Usaha maksimal dalam menerapkan teknik drainase yang saat ini sedang menjadi pilihan dalam rangka menghadapi global warming yaitu sistem drainase air hujan berwawasan lingkungan. Sistem ini menurut [Sunjoto, 2007] terdiri dari tiga kelompok yaitu Sumur Peresapan Air Hujan (Recharge Well), Parit Resapan Air Hujan (Recharge Trench) dan Taman Resapan Air (Recharge Yard) dan yang terakhir ini juga disebut Taman Bertanggul [Sujono, 2005].

Banjir (genangan air hujan) dan menurunnya permukaan air-tanah (groundwater) terjadi di berbagai kawasan perumahan. Hal tersebut menjadi rutinitas yang terjadi setiap tahun pada musim hujan dan musim kemarau, yang menyebabkan kerugian material yang sangat besar dan berdampak menurunnya harga perumahan secara dratis. Upaya yang dapat dilakukan adalah dengan pembuatan sumur resapan air hujan atau pembangunan pompa pengendali banjir.

Salah satu faktor yang menyebabkan banjir dan menurunnya permukaan air-tanah di kawasan perumahan adalah proses alih fungsi lahan. Proses alih fungsi lahan dari lahan pertanian atau hutan menjadi perumahan dapat menimbulkan dampak negatif, apabila tidak diikuti oleh upayaupaya menyeimbangkan kembali fungsi lingkungan. Di sisi lain dipicu oleh pengembangan fisik bangunan rumah yang terlalu pesat ke arah horisontal yang menyebabkan tidak adanya lagi area terbuka 
sebagai resapan air, sehingga air yang meresap ke dalam tanah menjadi terbatas dan memperbesar volume aliran permukaan.

Salah satu solusi untuk mengatasi banjir dan menurunnnya permukaan air-tanah pada kawasan perumahan adalah dengan cara pencegahan sedini mungkin melalui perencanaan dari awal oleh pihak pengembang perumahan (kontraktor / developer) dengan mengalokasikan lahan untuk pembuatan konstruksi sumur resapan air hujan atau pompa pengendali banjir.

Sistem drainase suatu kawasan perumahan biasanya direncanakan sesuai dengan jumlah volume air permukaan yang berasal dari rumah-rumah per-blok dengan kondisi rumah yang standar (rumah belum dikembangkan). Kondisi ini yang membuat dimensi saluran drainase tidak dapat menampung lagi volume air permukaan sejalan dengan pengembangan rumah-rumah, yang berakibat terjadinya genangangenangan air bahkan banjir pada kawasan tersebut dan sekitarnya.

Sumur resapan air merupakan rekayasa teknik konservasi air yang berupa bangunan yang dibuat sedemikian rupa sehingga menyerupai bentuk sumur gali dengan kedalaman tertentu yang berfungsi sebagai tempat menampung air hujan diatas atap rumah dan meresapkannya ke dalam tanah. Manfaat yang dapat diperoleh dengan pembuatan sumur resapan air antara lain : (1) mengurangi aliran permukaan dan mencegah terjadinya genangan air, sehingga memperkecil kemungkinan terjadinya banjir dan erosi, (2) mempertahankan tinggi muka air tanah dan menambah persediaan air tanah, (3) mengurangi atau menahan terjadinya intrusi air laut bagi daerah yang berdekatan dengan wilayah pantai, (4) mencegah penurunan atau amblasan lahan sebagai akibat pengambilan air tanah yang berlebihan, dan (5) mengurangi konsentrasi pencemaran air tanah.

Sumur resapan air ini berfungsi untuk menambah atau meninggikan air tanah, mengurangi genangan air banjir, mencegah intrusi air laut, mengurangi gejala amblesan tanah setempat dan melestarikan serta menyelamatkan sumberdaya air untuk jangka panjang.Oleh karena itu pembuatan sumur resapan perlu digalakkan terutama pada setiap pembangunan rumah tinggal.
Adanya sumur resapan dapat mengurangi volume air limpasan permukaan. Air hujan yang jatuh di atas permukaan atap bangunan rumah dialirkan melalui talang terus ditampung ke dalam sumur resapan. Dengan demikian, air hujan tidak mengalir ke mana-mana dan mengurangi air limpasan permukaan. Pemasangan sumur resapan dapat dilakukan dengan model individual dan komunal. Sumur resapan model individual adalah satu sumur resapan digunakan untuk satu rumah, sedangkan yang satu sumur resapan komunal digunakan secara bersamasama untuk lebih dari satu rumah.

Air hujan yang jatuh ke halaman rumah harus dapat diserap oleh lahan halaman rumah itu sendiri dan tidak melimpas ke luar halaman rumah. Halaman rumah secara alamiah dapat menyerap curahan air hujan, termasuk dari air hujan dari cucuran atap rumah, yang mengalir melalui talang. Dalam hal ini sumur resapan dapat ikut mengurangi sumbangan banjir dengan mengurangi volume runoff air hujan.

Masuknya air hujan melalui peresapan (infiltrasi) inilah yang menjaga cadangan air tanah agar tetap dapat dipanen dengan mudah. Permukaan air-tanah memang berubah-ubah, tergantung dari pasokan air dan eksploitasinya. Dengan memasukkan ke dalam sumur resapan, air hujan yang jatuh di areal perumahan tidak terbuang percuma ke selokan terus mengalir ke sungai.

Banjir dan menurunnya permukaan air tanah yang melanda beberapa kawasan perumahan telah berlangsung cukup lama dan bahkan telah dianggap sebagai rutinitas yang terjadi setiap tahun. Upaya yang dapat dilakukan untuk mengatasi hal tersebut adalah dengan membangun sumur resapan air pada setiap rumah dalam suatu kawasan perumahan atau membangun pompa pengendali banjir.

Sumur Resapan Air Hujan (Recharge Well) merupakan alternatif pilihan dalam mengatasi banjir dan menurunnya permukaan air tanah pada kawasan perumahan, karena dengan pertimbangan : a) pembuatan konstruksi SRA tidak memerlukan biaya besar, b) tidak memerlukan lahan yang luas, dan c) bentuk konstruksi SRA sederhana. Sumur resapan air merupakan rekayasa teknik konservasi air yang berupa bangunan yang dibuat sedemikian rupa sehingga menyerupai bentuk sumur gali dengan 


$$
\begin{aligned}
\mathrm{C}_{\text {tadah }}= & \text { koefisien limpasan dari bidang } \\
& \text { tadah (tanpa satuan) } \\
\mathrm{A}_{\text {tadah }}= & \text { Luas bidang tadah }\left(\mathrm{m}^{2}\right) \\
\mathrm{R}= & \text { Tinggi hujan harian rata-rata } \\
& \left(\mathrm{L} / \mathrm{m}^{2} / \text { hari }\right)
\end{aligned}
$$

2) Volume air hujan yang meresap digunakan rumus sebagai berikut :

$$
V_{r s p} \frac{t_{e}}{24} \cdot A_{\text {total }} K \text {....... }
$$

dimana :

$\mathrm{V}_{\text {rsp }} \quad=$ volume air hujan yang meresap $\left(\mathrm{m}^{3}\right)$

$\mathrm{t}_{\mathrm{e}}=$ durasi hujan efektif (jam)

$\mathrm{t}_{\mathrm{e}} \quad=0,9 \cdot \mathrm{R}^{0,92} / 60(\mathrm{jam})$

$\mathrm{R} \quad=$ tinggi hujan harian rata-rata $\left(\mathrm{L} / \mathrm{m}^{2} /\right.$ hari)

$\mathrm{A}_{\text {total }}=$ luas dinding sumur + luas alas sumur $\left(\mathrm{m}^{2}\right)$

$\mathrm{K}=$ koefisien permeabilitas tanah ( $\mathrm{m} / \mathrm{hari}$ ) (untuk dinding sumur yang kedap, nilai $\mathrm{K}_{\mathrm{v}}=\mathrm{K}_{\mathrm{h}}$, untuk dinding tidak kedap diambil nilai $\mathrm{K}_{\text {rata-rata }}$ )

$\mathrm{K}_{\text {rata-rata }}=\frac{\mathrm{K}_{\mathrm{W}} \mathrm{A}_{\mathrm{h}}+\mathrm{K}_{\mathrm{h}} \mathrm{A}_{\mathrm{W}}}{\mathrm{A}_{\text {total }}} \ldots \ldots$....

dimana;

$\mathrm{K}_{\text {rata-rata }}=$ koefisien permeabilitas tanah rata-rata (m/hari)

$\mathrm{Kv}=$ koefisien permeabilitas tanah pada dinding sumur ( $\mathrm{m} / \mathrm{hari})$

$=2 \mathrm{Kh}$

$\mathrm{Kh}=$ Koefisien permeabilitas tanah pada alas sumur (m/hari)

$\mathrm{Ah}=$ luas alas sumur dengan penampang lingkaran $=1 / 4 \pi$. $\mathrm{D}^{2} .\left(\mathrm{m}^{2}\right)$

$=$ luas alas sumur dengan penampang segi empat $=\mathrm{P}$. L . $\left(\mathrm{m}^{2}\right)$

$A_{v}=$ luas dinding sumur dengan penampang lingkaran $=\pi$. D. $\mathrm{H}\left(\mathrm{m}^{2}\right)$

$=$ luas dinding sumur dengan penampang segi empat $=2$. P . $\mathrm{L}\left(\mathrm{m}^{2}\right)$

3) Volume penampung (storasi) air hujan digunakan rumus sebagai berikut:

$$
\mathrm{V}_{\text {sstorasi }}=\mathrm{V}_{\mathrm{ab}}-\mathrm{V}_{\mathrm{rsp}}
$$

Penentuan jumlah sumur resapan air hujan, terlebih dahulu menghitung Htotal sebagai berikut:

$$
H_{\text {total }}=\frac{V_{a b}-V_{r s p}}{A_{b}}
$$

$$
\mathrm{n}=\frac{\mathrm{H}_{\text {total }}}{\mathrm{H}_{\text {rencana }}} \ldots . . .
$$

dimana :

$\mathrm{n} \quad=$ jumlah sumur resapan air hujan (buah)

$\mathrm{H}_{\text {total }}=$ kedalaman total sumur resapan air hujan (m)

$\mathrm{H}_{\text {rencana }}=$ kedalaman yang $\mathrm{di}$ rencanakan < kedalaman air tanah (m)

Penelitian yang pernah dilakukan Eka Ayu Indramaya dan Ig. L. Setyawan Purnama (2013) melakukan penelitian Rancangan Sumur Resapan air hujan sebagai salah satu usaha konservasi air tanah di perumahan Dayu Baru Kabupaten Sleman Daerah Istimewa Yogyakarta.

Penelitian yang serupa juga pernah dilakukan Nopandi Valentinus Parhusip dan Ivan Indrawan (2014) Penerapan Sumur Resapan pada Perencanaan Drainase Wilayah di Kecamatan Tarutung (Studi Kasus : Kawasan Permukiman Kelurahan Hutatoruan VII).

Penelitian Pembuatan Sumur Resapan Dalam Perumahan Sebagai Model Konservasi Air Tanah (Upaya Mempertahankan Air Tanah Akibat Dampak Pembangunan) bisa digunakan sebagai model pembuatan sumur resapan di wilayah Kabupaten Klaten sebagai syarat pembuatan sumur resapan saat dilakukan pembangunan yang menutup lahan terbuka dengan konversi luasan yang dibangun.

Penelitian ini akan membahas dan mengetahui bagaimana mendapatkan pola konversi lahan yang digunakan dalam pembangunan digantikan oleh adanya sumur resapan sebagai upaya konservasi air tanah agar mengacu kepada konsep pembangunan yang berkelanjutan. Sehingga akan didapatkan pengganti ruang terbuka yang digunakan untuk bangunan dengan sejumlah sumur resapan sebagai penggantinya.

Hasil penelitian ini bisa diimplentasikan dalam skala yang lebih besar dan luas untuk cakupannya sehingga dapat dipergunakan sebagai acuan dalam mengontrol dan mengendalikan kelestarian air tanah yang lebih luas lagi.

\section{METODE PENELITIAN}

Metode yang digunakan dalam penelitian ini dengan menggunakan metode survei sedangkan untuk analisis 
menggunakan analisis kuantitatif. Pengambilan sampel dilakukan dengan dua metode yaitu metode purposive sampling untuk pengukuran permeabilitas yang mempertimbangkan pengambilan sampel pada lahan yang belum diberi perkerasan seperti lahan kosong maupun pekarangan rumah sedangkan untuk pengukuran kedalaman muka air tanah dengan mengukur kedalaman permukaan air sumur eksisting dan dengan cara menggali rencana sumur resapan yang akan dipakai dalam komplek perumahan. Langkah-langkah pererncanaan sumur resapan mengikuti ketentuan dari SNI 03-2453-2002 (Tata cara perencanaan sumur resapan air hujan untuk lahan pekarangan). Beberapa parameter yang digunakan untuk menentukan desain sumur resapan antara lain:

Mengetahui Kedalaman Muka Air TanahKedalaman muka air tanah diketahui dari mengukur permukaan air sumur eksisting dan menggali rencana sumur resapan dan mengukur kedalaman permukaan air tanahnya.Mengetahui Nilai Permeabilitas TanahDalam Penelitian ini Nilai Permeabilitas Tanah dengan menggunakan persyaratan teknis struktur tanah yang mempunyai permeabilitas sedang (geluh kelaunan 2,0 - 3,6 cm/jam atau 0,48 - 0,864 $\mathrm{m} 3 / \mathrm{m} 2 / \mathrm{hari}$ ) berdasarkan dari hasil klasifikasi tanah galian untuk sumur resapan.

Langkah-langkah yang perlu diperhatikan dalam pembuatan sumur resapan air hujan adalah sebagai berikut :

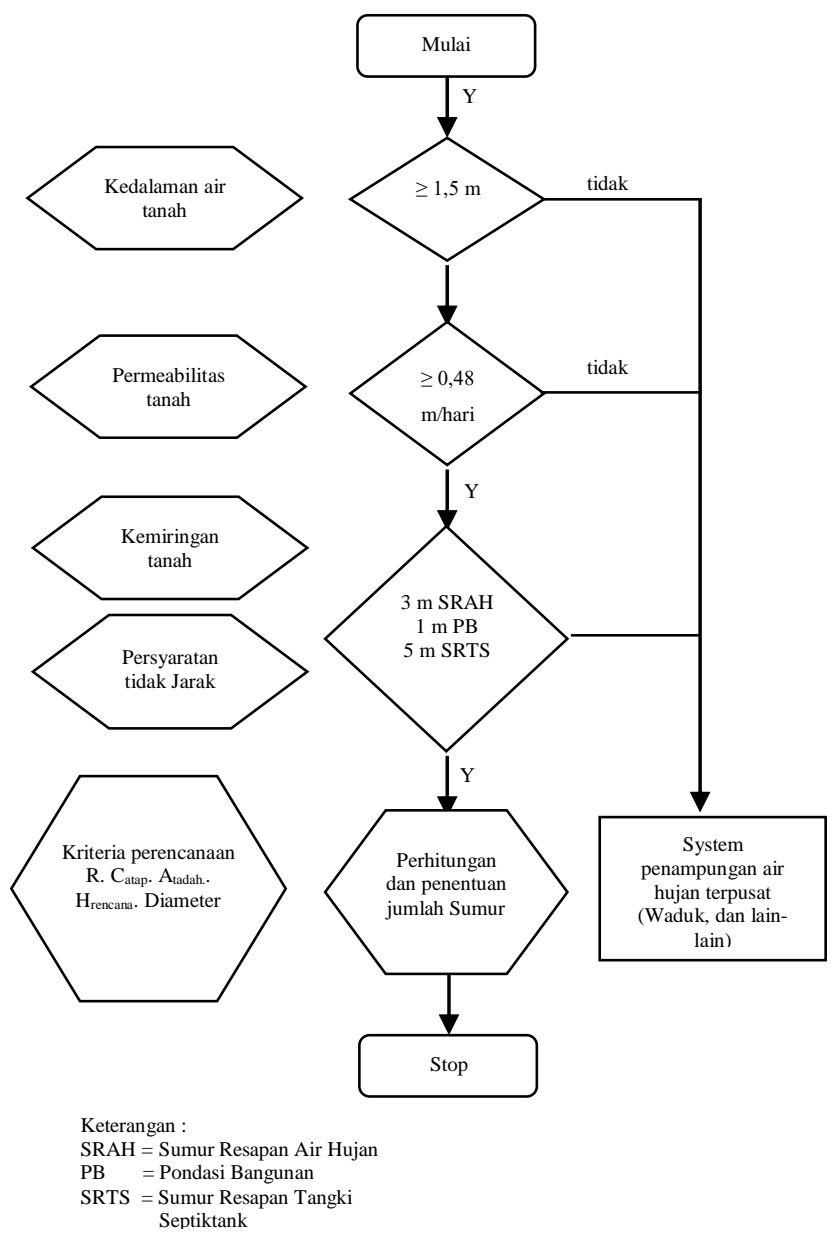

HASIL DAN PEMBAHASAN

Luasan area Klaster Perumahan Puri Klaseman Klaten lebih kurang $1.500 \mathrm{~m} 2$ dengan luas bangunan rumah dan lahan kaveling tertutup (carport) sebesar $650 \mathrm{~m} 2$ sedangkan untuk perkerasan jalan(paving block) $255 \mathrm{~m} 2$, sisanya $595 \mathrm{~m} 2$ berupa open space dan taman lingkungan.

Berdasarkan pendekatan perhitungan metode SNI 03-2453-2002 (Tata cara perencanaan sumur resapan air hujan untuk lahan pekarangan) rumus menghitung volume air limpasan permukaan pada bidang rumah dan carport, koefisien limpasan permukaan (runoff coefficient) dengan $\mathrm{C}=0.85$, tinggi curah hujan untuk wilayah Jawa dengan $\mathrm{R}=50 \mathrm{~mm} / \mathrm{hari}$.

\section{Analisa perhitungan Sumur resapan}

Dengan menggunakan Rumus Perhitungan Sumur Resapan pada Bidang Rumah sebagai berikut :

$\begin{array}{llrl}\mathrm{C}_{\text {tadah }} & = & 0,85 & \\ \mathrm{~A}_{\text {tadah }} & = & 650 & \mathrm{~m}^{2} \\ \mathrm{R} & = & 50 & \mathrm{~mm} / \mathrm{hari}\end{array}$




$\begin{array}{llrl}\mathrm{V}_{\mathrm{ab}} & =23619,38 & \mathrm{lt} \\ & = & 23,62 & \mathrm{~m}^{3} \\ \mathrm{D} & = & 1 & \mathrm{~m} \\ \mathrm{H} & = & 1,50 & \mathrm{~m} \\ \mathrm{~K}_{\text {tanah }} & = & 20 & \mathrm{~cm} / \text { jam } \\ & = & 4,80 & \mathrm{~m} / \text { hari } \\ \mathrm{K}_{\mathrm{h}=1 / 2 \mathrm{~K}_{\mathrm{v}}} & = & 2,40 & \mathrm{~m} / \text { hari } \\ \mathrm{t}_{\mathrm{e}} & = & 32,91 & \text { menit } \\ & = & 0,51 & \text { jam } \\ \mathrm{K}_{\text {rerata }} & = & 2,74 & \\ \mathrm{~K}_{\mathrm{v}} & = & 4,80 & \\ \mathrm{~A}_{\mathrm{h}} & = & 0,79 & \mathrm{~m} \\ \mathrm{~K}_{\mathrm{h}} & = & 2,40 & \\ \mathrm{~A}_{\mathrm{v}} & = & 4,71 & \mathrm{~m}^{2} \\ \mathrm{~A}_{\text {total }} & = & 5,50 & \\ \mathrm{~V}_{\text {rsp }} & = & 0,34 & \mathrm{~m}^{3} \\ \mathrm{~V}_{\text {storasi }} & = & 23,27 & \mathrm{~m}^{3} \\ \mathrm{H}_{\text {total }} & = & 29,65 & \mathrm{~m} \\ \mathrm{H}_{\text {rencana }} & = & 1,50 & \mathrm{~m} \\ \mathrm{n} & = & 19,77 & \mathrm{bh} \\ \mathrm{n} & & & \end{array}$

Dengan menggunakan Rumus Perhitungan Sumur Resapan pada Bidang Jalan Paving sebagai berikut :

\begin{tabular}{|c|c|c|c|}
\hline $\mathrm{C}_{\text {tadah }}$ & $=$ & 0,85 & \\
\hline $\mathrm{A}_{\text {tadah }}$ & $=$ & 255 & $\mathrm{~m}^{2}$ \\
\hline $\mathrm{R}$ & $=$ & 50 & $\mathrm{~mm} /$ hari \\
\hline \multirow[t]{2}{*}{$\mathrm{V}_{\mathrm{ab}}$} & \multicolumn{2}{|c|}{$=9266,063$} & lt \\
\hline & \multicolumn{2}{|c|}{$=9,266063$} & $\mathrm{~m}^{3}$ \\
\hline $\mathrm{D}$ & $=$ & 1 & $\mathrm{~m}$ \\
\hline $\mathrm{H}$ & $=$ & 1,5 & $\mathrm{~m}$ \\
\hline \multirow[t]{2}{*}{$\mathrm{K}_{\text {tanah }}$} & $=$ & 20 & $\mathrm{~cm} / \mathrm{jam}$ \\
\hline & $=$ & 4,8 & $\mathrm{~m} /$ hari \\
\hline $\mathrm{K}_{\mathrm{h}}=1 / 2 \mathrm{~K}_{\mathrm{v}}$ & $=$ & 2,4 & $\mathrm{~m} /$ hari \\
\hline $\mathrm{t}_{\mathrm{e}}$ & \multicolumn{2}{|c|}{$=32,9075$} & menit \\
\hline $\mathrm{K}_{\text {rerata }}$ & \multicolumn{2}{|c|}{$=2,742857$} & \\
\hline $\mathrm{K}_{\mathrm{v}}$ & $=$ & 4,8 & \\
\hline$A_{h}$ & $=$ & 0,79 & $\mathrm{~m}^{2}$ \\
\hline $\mathrm{K}_{\mathrm{h}}$ & $=$ & 2,40 & \\
\hline $\mathrm{A}_{\mathrm{v}}$ & $=$ & 4,71 & $\mathrm{~m}^{2}$ \\
\hline$A_{\text {total }}$ & $=$ & 5,50 & \\
\hline $\mathrm{V}_{\mathrm{rsp}}$ & $=$ & 0,34 & $\mathrm{~m}^{3}$ \\
\hline $\mathrm{V}_{\text {storasi }}$ & $=$ & 8,92 & $\mathrm{~m}^{3}$ \\
\hline $\mathrm{H}_{\text {total }}$ & $=$ & 11,37 & $\mathrm{~m}$ \\
\hline $\mathrm{H}_{\text {rencana }}$ & $=$ & 1,50 & $\mathrm{~m}$ \\
\hline $\mathrm{n}$ & $=$ & 7,58 & bh \\
\hline
\end{tabular}

\section{Pembahasan}

Volume yang bisa ditampung oleh sumur resapan pada areal rumah seluas 650 $\mathrm{m} 2$, koefisien limpasan permukaan (runoff coefficient) dengan $\mathrm{C}=0.85$, tinggi curah hujan untuk wilayah Jawa dengan $\mathrm{R}=50$ $\mathrm{mm} /$ hari. adalah $\mathrm{Vab}=23,62 \mathrm{~m} 3$. Volume air hujan yang meresap ke dalam tanah Vrsp $=0,34 \mathrm{~m} 3$. Volume penampung (storasi) air hujan Vstorasi=23,27 m3. Dengan demikian kebutuhan sumur resapan untuk menampung limpasan air hujan akibat dari tertutupnya lahan terbuka oleh rumah dan carport sebanyak 19,77 buah sumur resapan, dalam praktek dibuat 20 unit. Dengan dimensi sumur resapan diameter $1 \mathrm{~m}$, kedalaman $1,5 \mathrm{~m}$ atau 3 buah buis beton untuk setiap sumur resapan. Letak sumur resapan dalam penempatan di lokasi setiap unit kaveling diletakkan berada di open space bagian belakang rumah dan satunya lagi diletakkan di ruang terbuka (taman) depan rumah.

Sedangkan sebagai pengganti lahan yang tertutup oleh paving block seluas 255 $\mathrm{m} 2$, koefisien limpasan permukaan (runoff coefficient) dengan $\mathrm{C}=0.85$, tinggi curah hujan untuk wilayah Jawa dengan $\mathrm{R}=50$ $\mathrm{mm} /$ hari, volume yang bisa ditampung oleh sumur resapan $\mathrm{Vab}=9,27 \mathrm{~m} 3$. Volume air hujan yang meresap ke dalam tanah Vrsp $=0,34 \mathrm{~m} 3$. Volume penampung (storasi) air hujan Vstorasi=8,92 m3. Dengan demikian kebutuhan sumur resapan untuk menampung limpasan air hujan akibat dari tertutupnya lahan terbuka oleh paving block sebanyak 7,58 buah sumur resapan, dalam praktek dibuat 8 unit. Dengan dimensi sumur resapan diameter $1 \mathrm{~m}$, kedalaman 1,5 $\mathrm{m}$ atau 3 buah buis beton untuk setiap sumur resapan. Letak sumur resapan dalam penempatannya diletakkan disetiap perbatasan unit kaveling satu dengan lainnya berada dibawah saluran drainase jalan.

Plotting dalam gambar perencanaan area permukiman dengan lausan lebih kurang $1500 \mathrm{~m} 2$ dengan luas bangunan rumah dan lahan kaveling tertutup (carport) sebesar 650 $\mathrm{m} 2$ sedangkan untuk perkerasan jalan(paving block) $255 \mathrm{~m} 2$, sisanya $595 \mathrm{~m} 2$ berupa open space dan taman lingkungan sebagai berikut, 


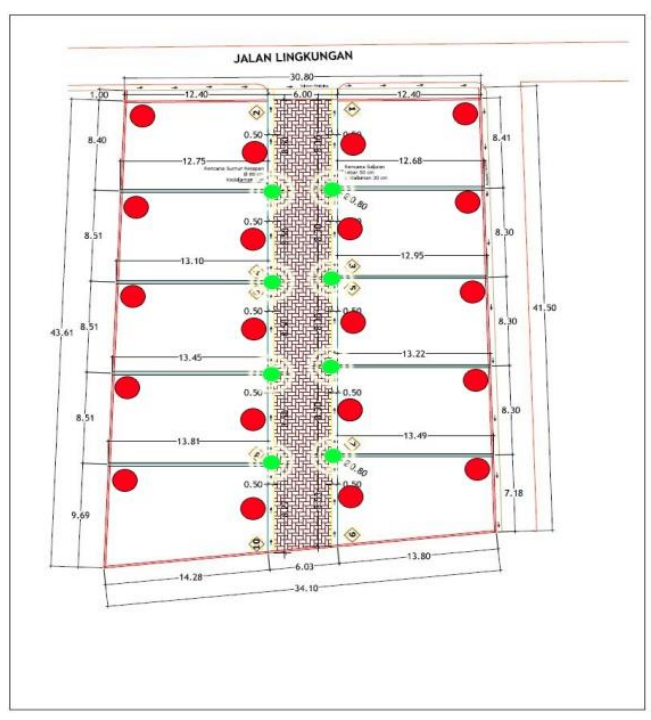

Gambar 1. Denah Site Plan

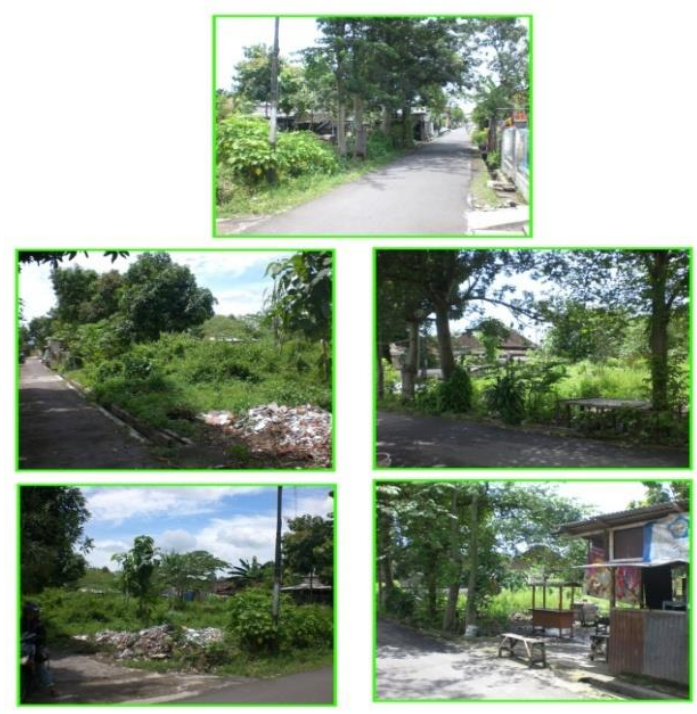

Gambar 2. Kondisi Eksisting
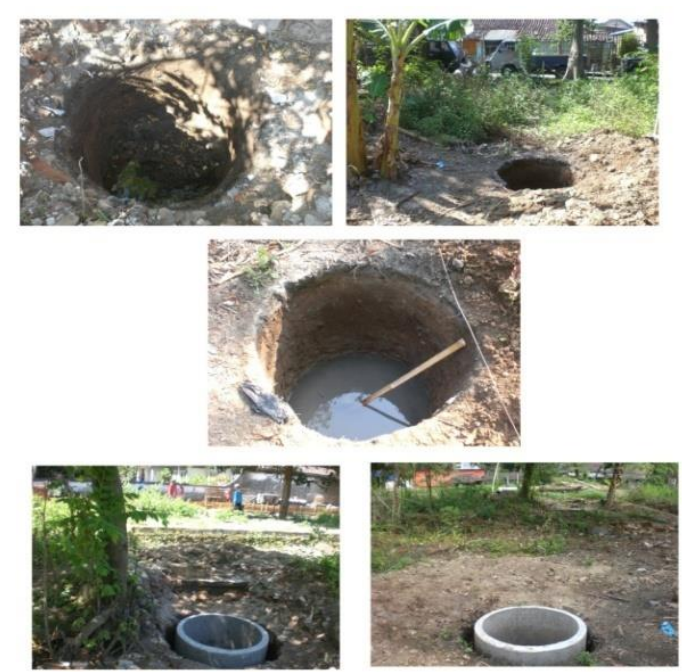

Gambar 3. Pembuatan Sumur Resapan

\section{KESIMPULAN DAN SARAN}

\section{Kesimpulan}

Jumlah sumur resapan yang dibangun pada kaveling sebagai penampung limpasan air hujan dari semua atap bangunan rumah dan carport sebanyak 20 unit yang diletakkan pada masing-masing unit kaveling setiap satu unit kaveling dibangun 2 unit sumur resapan, satu unit diletakkan dibagian belakang ruang terbuka kaveling dan satu unit diletakkan di bagian depan ruang terbuka rumah (taman) dengan dimensi sumur resapan diameter $1 \mathrm{~m}$, kedalaman 1,5 m.Jumlah sumur resapan yang dibangun pada sepanjang saluran drainase sebagai penampung limpasan air hujan dari jalan paving block sebanyak 8 unit yang diletakkan di perbatasan antar unit kaveling berada di bawah saluran drainase dengan dimensi sumur resapan diameter $1 \mathrm{~m}$, kedalaman 1,5 m.

\section{Saran}

Perlu diadakan penelitian lebih detail lagi untuk menentukan nilai permeabilitas tanah setempat agar akurasi data lebih baik, untuk menghitung volume air yang meresap ke dalam tanah. Mengingat karakteristik dari tanah di lingkungan Kabupaten Klaten bervariasi mulai dari tanah yang berpasir, lempung sampai bebatuan.Perlu data curah hujan pada stasiun terdekat dari wilayah penelitian untuk mendapatkan nilai tinggi hujan harian rerata yang mendekati nilai sebenarnya.

Penggunaan hasil penelitian bisa diimplementasikan untuk cakupan yang lebih luas lagi yakni untuk wilayah Kabupaten Klaten. Konversi pembuatan sumur resapan secara komunal bisa dialokasikan pada lahan terbuka hijau atau fasilitas umum baik yang berada di lingkungan perumahan maupun lingkungan terbuka lainnya milik pemerintah. Sehingga pembuatan sumur resapan bisa menggantikan cadangan resapan air tanah pada lahan/area yang tertutup oleh bangunan dan sarana lainnya.Demikian juga pada area industri perlu adanya kontrol pengendalian terhadap pembuatan sumur resapan atau area cekungan untuk menampung air limpasan permukaan sebagai pengganti muka tanah terbuka yang dipakai sebagai bangunan industri. 


\section{DAFTAR PUSTAKA}

Bradja M. Das. (1993). Mekanika tanah Prinsip-prinsip, rekayasa geoteknik, jilid 1. Jakarta: Penerbit Erlangga.

Badan Standardisasi Nasional. (2002). SNI

03-2453-2002, Tata Cara Perencanaan Sumur Resapan Air Hujan untuk Lahan Pekarangan.

Eka, A.,I., dan Ig. L. Setyawan P. (2013). Rancangan Sumur Resapan air hujan sebagai salah satu usaha konservasi air tanah di perumahan Dayu Baru Kabupaten Sleman Daerah Istimewa Yogyakarta.

Moh. Masduki Hardjosuprapto, Ir. (1999). Drainase perkotaan.

Nopandi V., P., dan Ivan I. (2014). Penerapan Sumur Resapan pada Perencanaan Drainase Wilayah di Kecamatan Tarutung (Studi Kasus : Kawasan Permukiman Kelurahan Hutatoruan VII).

Sunjoto. (2007). Peningkatan Tampungan Air Tanah Akibat Infiltrasi di Saluran, Pros. Lokakarya Nasional Rekayasa Penanggulanagan Dampak Pengambilan Air Tanah, Dept. ESDM. PLG, Jakarta 6 September 2007.

Sujono. (2005). Laporan Penelitian Survei Drainase Lingkungan Kampus, Yogyakarta. 